MATEC Web of Conferences 52, 02006 (2016)

DOI: $10.1051 /$ matecconf/20165202006

(C) Owned by the authors, published by EDP Sciences, 2016

\title{
Research on the Application of Tactile Materials to Design and Printing of Books
}

\author{
Wang Yuanyuan ${ }^{\text {a }}$ \\ Dalian Polytechnic University, Institute of Clothing, 116034 Dalian Liaoning, China
}

\begin{abstract}
China is a country with the most abundant forms of traditional books, and the evolution of book forms has special material characteristics. The Paper meets the demands of people on multi-sensory stimulation and spiritual experience not only through sense of touch taken as one of human body's multiple senses, but also through analyzing and researching the tactile materials generated based on the sense of touch and discussing how the tactile materials change the single visual experience of traditional paper media. Unique emotional experience and interactive experience brought by the tactile materials are the future book development direction. Through discussing application to contemporary culture and design thinking and introspection and more profoundly understanding the cultural connotation and the artistic value of the books, a newer way of development is provided for future development of paper books.
\end{abstract}

\section{Development of Book Materials}

Papermaking and printing invented are the most outstanding cultural heritage in China. As one of ancient forms of art design, book design has a long history and is rich in cultural connotation. In recent years, along with continuously steady and healthy development of economy and culture as well as science and technology, update of book design thinking, change of reader' reading ideas, increasingly-complete printing and publishing system and rapid development of new technologies and new materials, people have been propelled to look for new book forms, therefore, the traditional printing industry presents new development features.

Books are not only one of the important media for people's understanding of nature and understanding of the world, but also are culture's concrete carriers and media[1]. The evolution of Chinese books' forms has unique material characteristics, namely from the earliest inscriptions on oracle bones to bronze inscriptions, inscribed bamboo slips to silk and finally to the reel system and album system of paper materials, different influences and updates of the materials decide the external forms of the books.

The invented printing technology makes the books spread and stored and plays the roles of the most important cultural inheritance and communication. Printed materials are becoming more and more abundant along with continuous improvement of the printing technology. The updated printing technology has also expanded the scope of performance of materials. More types of substrates have offered the possibility in diversified development of book forms.

\footnotetext{
${ }^{a}$ Corresponding author : 763631431@qq.com
} 


\section{Tactile Materials and Printing}

The way of reading the books decides that this art form is not confined to the transmission of visual sense. When people pick up a book and gently read it, it is bound to be a behavioral activity closely linked with the tactile materials like a ceremony. Miller Ray once said, "the awakening of the mind comes from the body", which confirms that the suggestion of sensory stimulation to human psychology makes it easier for people to perceive the information transmitted by the books.

As the general term of mechanical stimulations such as contact, sliding, pressure and so on, the sense of touch is a kind of feeling caused as the slight mechanical stimulation makes the skin superficial layer receptor excited. A lot of tactile animals rely on the sense of touch to locate and recognize their living environment and capture their favorite foods. The human beings' tactile organs are all over the body. Taking contact stimulation on human body surface as an example, temperature, sense of pain, sense of touch and other feelings can be felt by means of free nerve endings of human skin. The skin is regarded as the outer layer of the human brain by us, which owns an extremelysensitive and rich sensory receptor. The skin, which is formed by tissues forming the brain, is the extension of the human brain. The tactile materials have widely applied to book design and printing industry in recent years, which are mainly reflected in two aspects of printed substrates and special printing technology.

\subsection{Substrates}

As most of traditional substrates are made of paper, along with continuous improvement of papermaking technology in recent years, there are many types of special paper, and paper patterns, textures, softness, density and other different textures can result in a big imagination space so as to bring along inspiration to book designers. For example, there are embossed paper with non-obvious patterns on the surfaces, hot bake paper of which the color is changed through pressing, dermatoglyph paper imitating organisms and animals, wove paper, silkworm cotton paper, velvet paper, abrasive paper with special sense of touch, bamboo paper, pressure sensitive paper with special functions, blueprint paper, thermal-sensitive paper and so on, which can generate materials with different senses of touch and become the new darling of book printing. In the processes of design and printing, although pictures and texts in the books belong to visual perception, each substrate is no longer a simple and traditional two-bit plane. Through touch, the unique physical properties of the substrates and the psychological touches caused in the delicate change can be felt.

Except for paper substrates, a lot of applied non-paper-made materials also provide more choices for the substrates of the books, like leather, special cloth, plastic, wooden boards, metal, silk cloth and so on. In the book Zhu Xi's Qianziwen designed by Lu Jingren serving as a Professor in China Central Academy of Fine Arts, about 1,000 words in the letter were engraved on paulownia wooden boards, and their engraving method imitates wood carving of printing in the Song Dynasty. In the whole letter, all the words were better put together through the belt, which form a book form with unique modeling. He said, "Zhu Xi's Qianziwen was engraved on the stones, which brings along a kind of feeling of cutting by knifes and axes. I hope that people can understand this strength from design and touch its grains".

\subsection{Special printing technique}

As in today of great impact on paper books, the ordinary printing process has difficultly met people's requirements and imagination on the books, the creation of tactile experience through the special printing process is one of future development directions of the books[2]. Through special technical processing performed on material surfaces by utilizing the modern printing process which is developing rapidly, the materials can better highlight their own characteristics, even the complex characteristics which are highlighted by various materials combined together and are superior to those displayed by single material. For example, stamping process (die stamping) is generally used for 
depressing and projecting title texts or cover patterns and can achieve texture effects of being rich in sense of touch and highlighting luxury; thermography can create a sense of hierarchy on one plane, even plain paper to give people different feelings and can also skillfully combine double senses, namely visual sense and sense of touch. In addition, there are laser engraving process, UV process, foil stamping process, flocking process, leather carving, die cutting and creasing and other special processes. Qian Cunxun once mentioned in the Chinese Paper and Printing that the continuouslyimproved process changed the performance of material surfaces and also presented a diversified trend in aspect of selection of book materials[3]. Appeared special paper enriches the texture and the beauty of the books. Applied non-paper materials enrich in the connotation of the books and make the books full of strong breath of times.

When Kenya Hara serving as a Japanese designer designs the program book for the opening ceremony of the Winter Olympics in Nagano, in order to highlight the beauty of ice and snow in the Winter Olympic Games, a kind of special paper, namely "ice and snow paper" was specially designed. On the soft paper as white as snow, the metal template for texts are heated and pressed on the paper through the special processes of denting and thermography, so that the text parts on the paper depress; under the action of heat, paper fibers are melted into translucent states, so that depressed typefaces achieve translucent effects like ice. This special book arouses people's memory of the original winter, reminds people of remembering the clusters of footprints left on the snowfield which is not stepped by others and effectively and artistically conveys the spirit of the winter Olympics[4].

\subsection{After-printing-technology}

After-printing-technology is the last link of printing, it's an important measure to consummate the printing quality and improve the aesthetic feeling and value of the products. It plays a decisive role in the final form and the applicability of the printings. Many books use after-printing-technology to complete the tactile materials. There is a special technology to deal with the spine, it is called the bare ridge binding. It make the sewing and glue of the book bare, this can make the book spared out completely and appear comfortable smoothly. What is more important, the designers want to show the internal binding structure of the books to the readers and let them touch it. In this way, the readers can comprehend a book through visual and feeling and have a double experience. Besides, there are also many other technology such as cutting technology, can also trigger people's aesthetic feeling. Qu Minyue and Jiang Qian used a special cutting technology in their book Dance of Dunhuang, which is the most beautiful book in China 2014, the edge of the kraft paper was specially designed to show the historical broken of the Dunhuang mural. The sound books of children also use the after-printingtechnology to add some thin and brittle paper into the mezzanine of these cloth art books. This help to develop children's intelligence through using their eyes, ears and fingers when they touch these hisses books.

The importance and particularity of printed materials are self-evident, and their significances are the results of designer's thinking[5].The advantages of the materials can be fully realized only through the appropriate process. An interactive relationship of mutual interrelation and promotion exists between the materials for printing the books and the process. The perfect process is conductive to embodying the peculiar language idea and feeling of the materials themselves. Therefore, more spaces are expanded for design and development of the books.

In recent years, in order to walk out of the bottleneck and get rid of the shackles caused by traditional forms, although the book design has been changed and broken through in aspects of design style, materials and special printing processes, many works ignored original function and meaning of the books for the purpose of seeking after gorgeous appearance and strong visual impact. Secondly, many books' design means are not better linked with the contents of the books and do not convey accurate themes in the books, so that form is greater than content, and a presumptuous guest usurps the host's role. Materials are the material basis of books, the selection of the materials can not be divorced from the original intention of the books, it has to make it clear that materials are for contents, 
and the values and significances of the books can be conveyed only by utilizing the material language reasonably and accurately.

\section{Multi-sensory Experience of Book Design}

Rapid development of times and update of new materials and new technologies drive the change of people's reading ideas. Internet, mobile phones and e-books have become the main ways for young people to read, so the traditional publishing industry and the printing industry are facing a huge impact. Changing the single visual experience caused by traditional paper media, developing the diversified design experience and meeting the demands of people on multi-sensory stimulation and spiritual experience are the future book development direction. Members in the reading experience team in University of Stavanger, Norway think that "reading is the interaction between people and technologies, and as the sense of touch and the physical properties of the printed books generate different cognitions and emotional experiences for people, it is especially important for people to focus on reading".

Organs for feeling outside things by human beings include eyes, mouth and nose, ears, skin and so on, namely stimulations caused by visual sense, sense of touch, sense of hearing, sense of smell and sense of taste as well as a variety of collections from these senses are integrated in the brain to finally form an image. When we read a book, the appearance, the weight, the color, the paper, the patterns and even the smell of ink emitted from books wholly form our understanding of the books. This is called unique interaction and experience transfer among all sensory organs (also known as the "synaesthesia"). The synaesthesia requires that the modern book design can stimulate the readers' sensual experience from all angles.

From another point of view, the innovative development of printing technology and process make full material preparations for design and printing of the modern books. As people's aesthetic requirements for the traditional books are getting higher and higher, the readers need to get a synesthesia experience of beauty from five senses. Taking children's books as an example, the traditional books take "paper" as a medium, and the children's books are difficultly confined to single materials, and their readers are eager to get more material touches from the books. Through study, psychologists have found out that the development of sense of touch is very important for children's psychological development. Some children's books are made of some cotton cloth or flannelette, thereby being soft, safe and environment-friendly and dust-proof. Toy books made of safe plastics can be prevented from being tore by children and be waterproof and cleanable cleaned, so that the children can take baths while reading. In addition, there are some natural books capable of training the children's sense of touch in a targeted manner, like "Journey of Nature" compiled by Rongxin Culture in which various special materials which imitate animal furs in nature are placed in its beautiful figures, so that while reading the books, the children like touching the wonderful natural world personally. The multiple sensitive explorations of sense of touch are conductive to children's action and cognitive development. The sense of touch is the basis of assisting other sensory systems to achieve functions. Based on the touch type books, the children can touch different materials in combination with the figures and recognize and identity that objects are smooth, soft, coarse and sharp. Through various stimulations, the children's perception of all kinds of things can be enhanced. American Dr. Ayres proposed the concept of sensory integration in 1972 and thought that the sensory integration is the ability that the human body effectively utilizes own sense organs in the environment to obtain and input information of different sensory pathways from the environment to the brain, and then the brain analyzes the inputted information for many times, performs overall treatment and makes adaptive response. Through sensory integration training, not only is the comprehensive development of children's visual sense, sense of hearing, sense of smell, sense of taste, sense of touch, vestibular sense and proprioceptive sense stimulated, but also the children's comprehensive integration ability is promoted.

The sense of touch is not the most important function of aesthetic appreciation, but is inextricably linked with visual aesthetic appreciation. The application of the tactile materials to book design makes 
people more strongly feel different skin textures and hardness of the books, even temperature and other differences in different aspects, which can bring along unique spiritual feeling to people[6]. Each material has its own expression and can express its own emotion and give people different psychological suggestions. For example, the grain materials have a warm feeling, the metal materials have a cold feeling, and the wood materials give people a natural and comfortable feeling. As material carriers having the communication functions and serving as artistic media, the materials self contain rich culture, and the culture is the important link to reflect the designers' ideas and convert book contents into materialized book forms, and the stress on the use of material thinking is a new design development direction of the modern books. Arnheim Rudolf says when taking about the sense of touch that art is from the body sense experience at any time and at any place[7]. The tactile experience is a tactile feeling of effectively stimulating and reflecting audiences participating in the design. The feeling caused by sense of touch is more subtle and delicate than that caused by visual sense and more can touch people's hearts.

\section{Future and Development of Tactile Materials in Book Printing}

Although China is a country with the most abundant forms of traditional books, it is short of new ideas in the design of modern books. Foreign excellent publishing houses and book designers have designed pop-up books, audio books, touch books, lift-the-flap books, interactive books and other multiple innovative books in succession. However, China is providing the services of printing in China and port-printing process at present only.

In August, 2003, the Shanghai Publishing and Press Bureau connected with the German Book and Art Foundation, decided to hold a selection called "the most beautiful book in China". This selection has been held 13 times so far, it had selected hundreds of books and helped them entered the "the most beautiful book in the world" selection. This is an important step of our country to change our character from printing country to designing country, with the help of the book competition in Leipzig, German, show our well-designed books to the world.

Lv Jing is a famous book artist in China. He is always paying his attention in the processing of the development of book art and founded the first professional platform in China to deal with process testing, commercial marketing, art exhibiting and academic exchanging.

He thinks that the design idea of the book design needs to be performed in combination with design, process and materials, the design only completes a small part of the whole book, and more attentions to design principle, artistic aesthetic feeling and cultural taste of the books must be paid[8]. We not only need to understand the properties of the materials and are proficient in the process application, but also dare to innovate and challenge the process. As special commodities, the books not only are used as text carriers to transmit the information, but also carry a nation's history, culture, folk life and art design. While facing a test, China's modern book design and printing industry adapt to new needs and seek for new development. Five-sense synesthesia-dominated design experience becomes the future book development trend. As the sense of touch is one of the important forms of human perception, if the tactile materials are blended into book design and printing, readers not only can passively accept during reading, but also experience the fun of interactive experience and are endowed with more special reading experiences.

This kind of touch experience is not a mordern touch screen technology, this new type of humancomputer interaction has replaced the traditional button panel, it can cmplete the operation and creat vivid video effects more simply,directly and naturally. But it still can't get rid of the fate of dealing with simple electronic products. All kinds of electronic products in modern life make people difficultly read deeply, and too much senses of science and technology and functional pursuit make people almost forget the fun of reading itself.

The fundamentality of design is to be people oriented and meet people's aesthetic needs. It is expected that there are more outstanding book designers in China in future, and more beautiful books enter Leipzig. It is expected that more readers realize the importance of emotion in book design and 
have a more profound understanding of cultural connotation and artistic value of the books, and a more new way of development is provided for future development of paper books.

\section{References}

1. X.J .Chen,Peking university press, paper (2012)

2. Y.D .Hu, Y.F. Zhang, Printing industry press ,Paper to print professional(2014)

3. C.X .Qian, Guangxi Normal University Press, Chinese paper and printing A Cultural History (2004)

4. Harakenya, Shandong people's publishing house, Design of design (2007)

5. J.P. Hao, Shanxi Normal University, Modern books design material of language study (2012)

6. W. Ding, Shanghai normal university, To explore the tactile design of books (2012)

7. Rudolf Arnheim, sichuan people's publishing house, visual thinking (1998)

8. J.R.Lv, China youth press, Book design (2009) 